\title{
CONCILIAÇÃO, MEDIAÇÃO E A FAZENDA PÚBLICA: MUDANÇA DE PARADIGMA E ENTRAVES POR SUPERAR
}

\section{CONCILIATION, MEDIATION AND PUBLIC TREASURY: PARADIGM SHIFT AND OBSTACLES TO OVERCOME}

\author{
${ }^{1}$ Emilio de Medeiros Viana \\ ${ }^{2}$ Iasna Chaves Viana
}

\section{RESUMO}

A Lei n ${ }^{\circ} 13.105 / 2015$ impõe novo modelo de atuação para o processo civil brasileiro. Busca-se induzir comportamento de diálogo genuíno entre os atores respectivos, como mitigação dos comportamentos não cooperativos. Coerente com o modelo proposto, sobreveio, ainda antes da vigência do novo CPC, a nova Lei de Mediação. As duas leis previram a possibilidade de que as fazendas públicas utilizem-se da mediação e da conciliação. Impuseram a criação de câmaras de mediação. Negligenciaram pontos que dificultam o êxito da empreitada, especialmente no que diz respeito às mediações ou conciliações das quais resulte obrigação de pagar dinheiro.

Palavras-Chave: Novo Código de Processo Civil. Lei 13.105/2015. Lei de Mediação. Lei 13.140/2015. Fazenda Pública.

\begin{abstract}
Law 13.105 / 2015 imposes a new model for Brazilian civil proceedings. It seeks to induce genuine dialogue behavior among the respective actors, such as mitigating non-cooperative behavior. Consistent with the proposed model, the new Mediation Law was still in force, even before the new CPC was in effect. Both laws provided for the possibility of public farms to use mediation and conciliation. They imposed the creation of mediation chambers. They have neglected points that hinder the success of the enterprise, especially with regard to mediations or conciliations resulting in an obligation to pay cash.
\end{abstract}

Keywords: New Civil Process Code. Law 13.105/2015. Mediation Act. Law 13.140/2015. Treassury Public.

\footnotetext{
${ }^{1}$ Doutorando em Direito Constitucional pela Universidade de Fortaleza - UNIFOR, Ceará, (Brasil). Especialista em Direito Processual Civil/UNIFOR. Professor do Centro Universitário 7 de Setembro - Uni7, Fortaleza, Ceará. Juiz de Direito no Ceará. E-mail: emilio.viana71@gmail.com

${ }^{2}$ Mestranda em Direito Privado pelo Centro Universitário 7 de Setembro - Uni7, Fortaleza, Ceará, (Brasil). Especialista em Direito Tributário pelo Instituto Brasileiro de Estudos Tributários - IBET. Membro do Grupo de Pesquisa em Tributação Ambiental - UFC/CNPq. Advogada. E-mail: iasnaviana@yahoo.com.br
} 


\section{INTRODUÇÃO}

A Lei $n^{\circ} 13.105 / 2015$ impõe novo modelo de atuação para o processo civil brasileiro. Busca-se induzir comportamento de diálogo genuíno entre os atores respectivos, com mitigação dos comportamentos não cooperativos.

O que se pretende é que o processo passe a ser entendido e tratado como comunidade de trabalho, onde todos que nele atuam - juízes, partes, procuradores, Ministério Público contribuam para a construção de decisões melhores e, portanto, mais aptas para o atingimento do fim último da prestação jurisdicional - é dizer, a efetiva pacificação do conflito que originou o processo.

A tentativa, portanto, é de minimização da cultura do litígio, substituindo a figura central do juiz pela via da composição dialógica dos conflitos, inclusive na esfera extrajudicial (CAMBI e VASCONCELOS, 2015, p. 83).

Firme na proposta de superação do modelo adversarial que, classicamente, caracterizou o processo civil brasileiro, o legislador editou, ainda durante o período de vacatio legis do novo Código de Processo Civil, a nova Lei de Mediação (Lei n ${ }^{\circ}$ 13.140/2015). As novações legislativas aprimoram a política pública que o Conselho Nacional de Justiça pretendeu empreender, a partir da edição da Resolução nº 125/2010.

Um e outra (código e lei) estabeleceram a possibilidade da utilização das soluções autocompositivas pelas fazendas públicas, recomendando, inclusive, a criação de câmaras de mediação em todas as esferas estatais (União, Estados, Municípios e Distrito Federal).

A questão é relevante, mormente se for levado em conta que a Fazenda Pública, consideradas as diversas esferas, é o maior repeat player que há no Brasil ${ }^{3}$.

Diante de tal contexto, importa discutir limites e possibilidades da utilização da mediação e conciliação pelas fazendas públicas.

A partir de pesquisa bibliográfica e dos dispositivos legais que regem a espécie, descritiva e exploratória, são apontados avanços e destacados problemas ainda por serem superados, de forma a tornar efetiva a possibilidade de que as contendas envolvendo a Fazenda Pública possam ser solucionadas também por meio de mediação e/ou conciliação.

3 A afirmação é Marcelo Veiga Franco, a partir da análise de estudo desenvolvido, em 2009, pela UFMG. Naquele ano, $60 \%$ das demandas que tramitavam no TJRS e $45 \%$ das que tramitavam no TJMG envolviam entidades públicas como parte. Em São Paulo, no ano de 2010, a situação era ainda mais grave: $48 \%$ das demandas com litigantes habituais envolviam o Estado de São Paulo, 22\% tinham a União como parte e $19 \%$ diziam respeito às administrações municipais. (FRANCO, 2015, p. 254-255) 


\section{O NOVO PARADIGMA LEGISLATIVO DO PROCESSO CIVIL BRASILEIRO: O MODELO COOPERATIVO/COMPARTICIPATIVO}

O paradigma legislativo do processo civil brasileiro já não era capaz de permitir adequado enfrentamento da realidade de que padece o Judiciário nacional. Construído sob o regime constitucional pretérito, o Código de Processo Civil de 1973 mantinha a função tradicional da magistratura brasileira, de arbitramento e resolução dos conflitos individuais.

A superveniência da Carta Constitucional de 1988 e a moderna dogmática dos direitos fundamentais impuseram substancial elevação do número e da complexidade das demandas que lhe são submetidas. O Judiciário viu-se envolvido no processo de transição do regime autoritário para a democracia - em plena crise mundial do welfare state. Estabeleceu-se discussão sobre o tipo de relação que deveria prevalecer entre as dimensões do público e do privado.

A nova postura acabou ensejando protagonismo judicial, efeito colateral da transição para a democracia. A crise de eficiência de que hoje padece o Judiciário, portanto, resulta da necessidade de sua adaptação abrupta à feição contemporânea da sociedade brasileira, sem que estivesse equipado material, conceitual e doutrinariamente para a carga de novos problemas que a sociedade passou a lhe apresentar (VIANNA; CARVALHO; MELO e BURGOS, 1997, p. 1112).

O quadro agrava-se cada vez mais. A avassaladora e sempre crescente carga de processos $^{4}$, as metas anualmente impostas pelo Conselho Nacional de Justiça e pelas corregedorias de cada tribunal (não raras vezes, sem consideração das peculiaridades estruturais e de pessoal de cada unidade judiciária) e a pressão exercida pelas próprias partes (que já não suportam aguardar pela crônica incapacidade do Judiciário de prestar um serviço adequado em tempo razoável) adoecem o juiz brasileiro ${ }^{5}$.

A situação de caos estrutural evidencia antagonismo no agir dos julgadores e das partes (e de seus advogados), os primeiros preocupados com a otimização numérica de seus julgados

\footnotetext{
4 Apenas em 2015 tiveram início 27,3 milhões de processos novos. Na mesma época, havia um estoque de 74 milhões de processos pendentes e apenas 17.338 cargos de juiz no Brasil. Dados disponíveis em http://www.cnj.jus.br/files/conteudo/arquivo/2016/10/b8f46be3dbbff344931a933579915488.pdf, acessado em 12/01/2017.

5 Tanto que, preocupado com o inquietante crescimento do número de afastamentos da atividade por problemas de saúde dela decorrentes, o Conselho Nacional de Justiça recentemente editou a Resolução $\mathrm{n}^{\circ} 207$, que institui a política de atenção integral à saúde de magistrados e servidores do Poder Judiciário, texto aprovado em 15/10/2015, publicado no DJ-e $n^{\circ} 1888$, de 21/10/2015, pp. 3/5, disponível em http://www.cnj.jus.br/buscaatos-adm?documento=3011, sítio eletrônico acessado em 08/11/2015.
} 
(redução das taxas de congestionamento), os demais no âmbito do litigar estratégico, com preocupação exclusiva de êxito. A patologia aparta-se do modelo constitucionalmente delineado para o processo.

A introdução de nova base normativa do processo pretende induzir comportamento de diálogo genuíno entre os atores do processo, como mitigação dos comportamentos não cooperativos (THEODORO Jr.; NUNES; BAHIA e PEDRON, 2015, p. 69).

O que se pretende é que o processo passe a ser entendido e tratado como comunidade de trabalho, onde todos que nele atuam - juízes, partes, procuradores, Ministério Público contribuam para a construção de decisões melhores. Não se trata de visão ingênua, que ignora os interesses divergentes das partes e o desejo do juiz de dar vazão à carga de trabalho que sobre ele recai. O que se tem em mente são os elevados custos da atividade não cooperativa. $O$ que se propõe, como superação, é a efetivação de um modelo de processo constitucionalmente adequado, que leva a sério o contraditório como possibilidade de influência e não surpresa e tenta primar por um comportamento objetivamente vinculado à boa-fé objetiva - modelo de comparticipação (THEODORO Jr.; NUNES; BAHIA e PEDRON, 2015, p. 70).

Referido modelo pretende superar visão de protagonismo judicial que emergiu da interpretação e aplicação do Texto Constitucional de 1988. O dever de cooperação não supõe a atuação da parte contra seus próprios interesses, mas impõe dever de agir com boa-fé. O que importa já não é que se chegue a qualquer decisão. Tampouco a decisão será correta porque é justa (o que implicaria em sobrecarga moral para juízes e partes). A decisão será constitucionalmente adequada quando para ela tiverem tido a possibilidade de efetivamente contribuir, sem abdicação do direito de agir em prol de seus próprios interesses, todos os atores do processo (THEODORO Jr.; NUNES; BAHIA e PEDRON, 2015, p. 70).

Reforce-se a ideia de que, nos últimos tempos, a atuação do Conselho Nacional de Justiça tem estimulado construção de modelo de governança judicial que se preocupa mais com números (produtividade), sempre na perspectiva de reduzir as taxas de congestionamento processual, do que com qualidade das decisões.

A ideia de um modelo policêntrico de processo representa, em última análise, superação de referido paradigma de atuação judicial, em prol da construção de decisões melhores. No modelo cooperativo, o juiz já não atua sozinho, de forma solipsista, na condução do processo. As partes e demais atores, inclusive advogados, devem contribuir na construção de decisão constitucionalmente adequada.

Foi com o deliberado propósito de propor aos atores judiciais nova postura que o novo 
Código de Processo Civil (Lei $n^{\circ}$ 13.105/2015) devotou capítulo inicial às assim designadas normas fundamentais do processo. Buscou-se, então, evidenciar normas (regras e princípios) que são extraíveis do modelo de processo delineado na Carta Constitucional de 1988.

Sem ser exaustivo ${ }^{6}$ (ali não se alude ao princípio do juiz natural, por exemplo), o Código de Processo Civil/2015 dispôs a respeito da inafastabilidade da jurisdição (com estímulos à conciliação e à mediação, art. $\left.3^{\circ}\right)$, da razoável duração do processo $\left(\operatorname{art.} 4^{\circ}\right)$, da necessidade de atuação no processo com boa-fé (art. $5^{\circ}$ ), da cooperação (art. $6^{\circ}$ ), do contraditório efetivo, com paridade de armas (art. $7^{\circ}$ ) e direito de participação na formação das decisões judiciais, com dever de consulta (arts. $9^{\circ}$ e $10^{\circ}$ ), do respeito à dignidade da pessoa humana, com atenção aos princípios da proporcionalidade, da razoabilidade, da legalidade, da publicidade e da eficiência (art. $8^{\circ}$ ), da publicidade dos atos judiciais (art. 11) e da observância preferencial da ordem cronológica no ato de proferir acórdão e sentenças de mérito (art. 12) ${ }^{7}$.

O modelo cooperativo de processo, aqui já aludido, impõe aos atores do processo que, em respeito à boa-fé objetiva, atuem no sentido da construção da melhor decisão possível, em comunidade de trabalho.

O que se está a propor, então, é a condução de processo com efetiva participação de todos que nele atuam, com vedação de decisões adotadas de surpresa e de agires que não contribuam adequadamente para o desenvolvimento regular do processo. Por outras palavras, a construção de um processo a partir da atuação conjunta de todos que nele atuam, sem protagonismos e com olhos postos na construção da melhor decisão possível.

Fala-se em mudança de postura porquanto parece evidente que a realização de um processo com tais características provavelmente demandará maior consumo de tempo, ao menos até a decisão de primeiro grau. Mas o processo é feito para durar, ao menos pelo tempo razoável para adequada construção da solução do conflito ${ }^{8}$.

Uma decisão melhor construída, a partir da efetiva participação na condução do processo de todos atores que nele atuam, potencialmente desafiará menos recursos e aqueles que vierem a ser manejados tenderão à rejeição. No limite, pois, a adoção de um modelo cooperativo/comparticipativo do processo contribuirá para uma solução definitiva mais rápida

6 Enunciado no 369 do Fórum Permanente de Processualistas Civis (FPPC): "O rol de normas fundamentais previsto no Capítulo I do Título Único do Livro I da Parte Geral do CPC não é exaustivo."

7 Observe-se que a regra da cronologia, inserida redação original do art. 12 do CPC/2015, foi modificada ainda antes do final do período de vacatio legis. A Lei $\mathrm{n}^{\mathbf{0}}$ 12.356/2016 modificou a redação, mitigando a regra da cronologia (já que foi seria inserido na respectiva redação o advérbio preferencialmente.

8 Sobre a noção de que o processo é feito para durar e a adequada compreensão do conceito de duração razoável do processo, veja-se Antônio do Passo Cabral (CABRAL, 2015, p. 2014, p. 101-122). 
(ainda que eventualmente mais demorada em primeiro grau de jurisdição) e mais segura. Melhor para o jurisdicionado, portanto.

Nessa perspectiva, a observação de Humberto Theodoro Jr., Dierle Nunes, Alexandre Bahia e Flávio Quinaud Pedron, para quem o debate bem realizado induz melhor aproveitamento e menor tempo quando se enxerga o processo do modo panorâmico, ainda mesmo que, momentaneamente (durante a tramitação do feito em primeiro grau de jurisdição), o gasto cronológico seja superior (THEODORO Jr.; NUNES; BAHIA e PEDRON, 2015, p. 164).

Ao mesmo tempo em que oferece um modelo constitucionalmente mais adequado de processo judicial (o processo cooperativo/comparticipativo), o legislador brasileiro propõe a superação da clássica visão do Judiciário como caminho preferencial para a solução dos conflitos surgidos no seio da sociedade.

Como já restou anotado, ficou estabelecido, dentre as normas fundamentais, a necessidade de que o Estado promova, sempre que possível, solução consensual dos conflitos. Os juízes e os demais atores do processo (advogados, defensores públicos, membros do Ministério Público) estão obrigados a estimular a conciliação, a mediação e outros métodos de solução consensual de conflitos (art. $3^{\circ}, \S \S 1^{\circ}$ a $3^{\circ}$ do CPC/2015).

Posteriormente, ainda durante o período de vacatio legis do novo Código de Processo Civil, veio a lume a Lei no 13.140/2015 (a chamada Lei de Mediação).

Para além de um modelo cooperativo de processo, portanto, o legislador brasileiro aponta a necessidade de desjudicialização da solução de conflitos.

Em tal contexto, importa analisar, para os fins do presente trabalho, as perspectivas e as dificuldades de implementação de uma política de desjudicialização, notadamente na seara da Fazenda Pública.

\section{CONCILIAÇÃO, MEDIAÇÃO E A FAZENDA PÚBLICA}

Tal qual restou anotado na introdução, a questão por ser aqui enfrentada diz com a repercussão do modelo de processo introduzido pelo novo Código de Processo Civil e pela nova Lei de Mediação, notadamente no que diz respeito aos conflitos que envolvem a Fazenda Pública

Crônica a incapacidade do aparelho judicial brasileiro de ofertar resposta minimamente adequada à quantidade e à complexidade crescente de demandas que lhe são 
submetidas.

Ciente da circunstância, o Conselho Nacional de Justiça editou, já em 2010, a Resolução $\mathrm{n}^{\mathrm{o}}$ 125, que institui a política nacional de tratamento adequado dos conflitos de interesses no âmbito do Poder Judiciário.

A melhor doutrina anotou, desde o primeiro momento, que a edição de referido ato normativo não se voltava para o combate à morosidade judicial. Visou, antes, ofertar método para tratamento mais adequado dos conflitos de interesses surgidos no seio da sociedade (WATANABE, 2013, p.43).

O cotidiano judicial, não raras vezes, contrariou a orientação. Incentivaram-se, por exemplo, semanas de conciliação muitos mais preocupadas com quantidade e com diminuição do estoque de processos do que com a efetiva construção de consensos e, portanto, de soluções efetivas para as controvérsias. Tal postura, algumas vezes, ameaçou soar como eloquente denegação de prestação jurisdicional.

Não há resquício de dúvida, contudo, de que o movimento deflagrado pela edição da aludida Resolução $n^{\circ}$ 125/2010, do Conselho Nacional de Justiça, marca decisivamente a mudança de paradigma que se sedimenta com a recente edição do novo Código de Processo Civil (Lei $n^{\circ} 13.105 / 2015$ ) e, sobretudo, da nova Lei de Mediação (Lei $n^{\circ} 13.140 / 2015$ ): institucionaliza-se um sistema de justiça multiportas.

Com efeito, a superveniência do ato normativo em referência transforma aqueles que eram tradicionalmente designados de meios alternativos de solução de conflitos (a arbitragem ${ }^{9}$, a conciliação e a mediação ${ }^{10}$ ) em meios integrados de solução de conflitos (CUNHA, 2016, p. 637).

A mudança não é apenas terminológica. Propõe passo adiante na noção de que a via judicial seria a preferencial para a solução de qualquer conflito (por isto, na visão tradicional, os demais meios de solução eram designados de alternativos).

Assim, estimulam-se e orientam-se os litigantes a buscarem a solução mais adequada para os seus conflitos - que, não necessariamente, é a solução que seria adjudicada pela prestação jurisdicional do Estado.

O ato normativo sob enfoque, contudo, padece de equívoco insuperável, qual seja, a

9 A experiência da arbitragem no Brasil ganhou corpo a partir a Lei n ${ }^{\circ}$ 9.307/96. O universo restrito de efetiva utilização das potencialidades da arbitragem, contudo, não foi capaz de impactar significativamente o sistema de Justiça no Brasil. De mais a mais, trata-se de hipótese de heterocomposição que, por esta razão, refoge ao âmbito de abordagem do presente trabalho.

10 Costumeiramente designados de Alternative Dispute Resolutions - ADR. 
crença de que o Poder Judiciário possui capacidade operacional (humana, orçamentária, estrutural) de recrutar, cadastrar e treinar pessoas com o perfil adequado para a realização de conciliação e/ou de mediação, bem assim para criar, instalar e fazer funcionar centros judiciários de solução de conflitos e cidadania nos mais distantes rincões do país.

A iniciativa lastreia-se em diretriz fixada pela Resolução $\mathrm{n}^{\circ} 70^{11}$ do próprio Conselho Nacional de Justiça, qual a de que constitui objetivo estratégico do Poder Judiciário estimular a ampliação ao sistema de justiça, compreendido da maneira mais abrangente possível (que engloba os antes designados meios alternativos de solução de conflitos).

$\mathrm{O}$ vício de que padece não lhe retira o mérito. Como sustentado, a edição da Resolução $\mathrm{n}^{\mathrm{o}}$ 125, do Conselho Nacional de Justiça, marca mudança de compreensão dos conceitos de acesso à justiça e de tratamento adequado dos conflitos, estimulando, sempre, a melhor solução para eles - e afastando, portanto, a falsa noção de que a solução judicialmente adjudicada seria sempre a melhor.

É sob a inspiração da Resolução $n^{\circ} 125$, do Conselho Nacional de Justiça, que são construídos o novo Código de Processo Civil e a Lei de Mediação.

O novo Código de Processo Civil institucionaliza os meios integrados de solução de conflitos, transformando o Judiciário, que passa a ser visto não mais apenas como espaço de julgamento, mas de efetiva resolução de conflitos. A explícita adoção de um sistema multiportas redimensiona e democratiza o papel do Poder Judiciário e o modelo de prestação jurisdicional (CUNHA, 2016, p. 651). O distanciamento e o formalismo típico dos atos judiciais tradicionais, nos quais a parte só se manifesta se e quando perguntada, normalmente em inquirição que visa levar-lhe à confissão, são substituídos por diálogo franco, com figura igualmente imparcial, devidamente treinada para o mister e que não se ocupa de apontar quem tem razão, mas apenas de estimular o diálogo.

A noção ampliada de acesso à justiça, para abranger não apenas a possibilidade de solução do conflito por meio da outorga da prestação jurisdicional, mas também os meios integrados, inaugura nova era. O objetivo do processo já não é mais apenas o julgar. O processo civil brasileiro ingressa na fase do processo como local de diálogo e de busca pelo melhor caminho para a resolução de cada disputa (CUNHA, 2016, p. 653). Ingressa-se, afinal, na terceira onda de acesso à justiça (CAPPELETTI e GARTH, 1988, p. 68-71).

11 A Resolução n ${ }^{\circ}$ 70/CNJ vigia quando da edição da Resolução no $125 / C N J$. Posteriormente, contudo, foi revogada e substituída pela Resolução $n^{\circ} 198 / C N J$, de $1^{\circ}$ de julho de 2014 , que atualizou os objetivos estratégicos do Poder Judiciário Nacional. 
Destaque-se que efetiva democratização do acesso à justiça importa não apenas em ampliar "portas de acesso"; mais que isto, impõe-se respeito às autonomias dos cidadãos, não apenas no momento da gênese do direito, mas sobretudo no momento da aplicação (NUNES e TEIXEIRA, 2013, p. 67), importa dizer, no momento de escolher a forma mais adequada de compor o litígio acaso surgido.

Já restou anotado que, logo nas normas fundamentais, o novo Código de Processo Civil erige a arbitragem, a composição e a mediação a meios integrados de solução de conflitos. Afasta-se, para os fins da discussão por ser aqui travada, a arbitragem, que é meio de solução heterocompositiva do litígio (terceiro, que é o árbitro, dita a decisão que vai solucionar o conflito, observadas as regras próprias da arbitragem).

A mediação e a conciliação são meios autocompositivos de solução do litígio. Nelas atua terceiro imparcial, com dever de confidencialidade (o mediador ou o conciliador), que conduz o diálogo entre as partes, de forma a possibilitar que elas alcancem a solução do conflito.

A mediação é mais adequada para as situações em que haja vínculo precedente entre as partes (questões familiares ou societárias, por exemplo). $\mathrm{O}$ mediador não sugere solução. Limita-se a auxiliar os interessados a compreender questões e interesses em conflito, de modo que possam, pelo restabelecimento da comunicação entre eles, identificar soluções consensuais que gerem benefícios mútuos.

A conciliação tem lugar, preferencialmente, nas situações em que não há vínculos anteriores entre as partes (como nas colisões de veículos, por exemplo). O conciliador pode sugerir soluções, sem jamais constranger ou intimidar partes na busca da solução adequada.

Em qualquer caso, os envolvidos devem receber informações quantitativas e qualitativas sobre a composição que podem realizar, com advertências a respeito das consequências dos acertos havidos e dos riscos deles eventualmente resultantes ${ }^{12}$.

Coerente com a premissa que assumiu - qual a de que a solução outorgada judicialmente não é, necessariamente, a melhor - , o novo Código de Processo Civil estabeleceu, como regra, que o juiz, ao despachar a inicial, designará audiência de conciliação ou mediação (art. 334). A audiência somente não ocorrerá se as duas partes manifestarem desinteresse na realização do ato $^{13}$ ou se a controvérsia posta em litígio não admitir

12 Até a superveniência do novo Código de Processo Civil, não havia marco legal distinguindo conciliadores e mediadores. A distinção foi feita nos $\S \S 2^{\circ}$ e $3^{\circ}$ do art. 165 do novo CPC. A Lei da Mediação (Lei $n^{\circ}$ 13.140/2015), por sua vez, agora, descreve pormenorizadamente a atuação dos últimos. Para mais detida distinção doutrinária a respeito das possibilidades de atuação de um e outro Lilia Maia de Morais Sales (SALES, 2003, p. 38) e Fernanda Tartuce (TARTUCE, 2015, p. 177).

13 Malgrado a clareza da letra da lei, parte da doutrina tem sustentado a desnecessidade de realização do ato, por 
autocomposição.

A regra que autoriza a não realização da audiência no caso de inviabilidade de autocomposição (art. 334, § $4^{\circ}$, II, do novo CPC) tem sido sistematicamente invocada para afastar a realização do ato quando a Fazenda Pública está em juízo.

Ocorre que nem sempre o direito de que é titular a Fazenda Pública é indisponível ${ }^{14}$.

Com o deliberado propósito de afastar a oposição de óbices genéricos à possibilidade de utilização de meios consensuais de solução pelas Fazendas Públicas, o art. 174 do novo Código de Processo Civil expressamente dispôs que a União, os Estados, o Distrito Federal e os Municípios criarão câmaras de mediação e conciliação, com atribuições relacionadas com a solução consensual de conflitos no âmbito administrativo. De forma exemplificativa - importa dizer, por evidente, que poderão ser realizadas composições e mediações sobre matérias diferentes daquelas que ali estão elencadas -, dispôs que as composições poderiam envolver solução de conflitos entre órgão e entidades de administração pública e celebração de termos de ajustamento de conduta. Ali igualmente restou prevista a possibilidade de avaliação da admissibilidade de pedidos de resolução de conflitos por meio de conciliação no âmbito da administração pública.

Atente-se para a forma verbal utilizada pelo legislador: criarão. Trata-se de ordem, portanto, que não pode ser negligenciada.

A providência é coerente com as diretrizes fixadas na parte geral do novo Código de Processo Civil, que busca instituir uma nova cultura jurídica, qual seja, a da consensualidade.

De mais a mais, a circunstância de as Fazendas Públicas terem se tornado litigantes habituais contribui decisivamente para o estado falimentar da estrutura judiciária brasileira. Em rigor, a judicialização excessiva e desnecessária aparta-se do interesse público primário (inclusive no que diz respeito à proteção econômica do patrimônio público e do erário). A desjudicialização da solução dos conflitos que envolvem as Fazendas Públicas, assim entendida a possibilidade de controle da atuação estadual por meios integrados de solução de conflitos, permite que o cidadão participe ainda mais ativamente da gestão da res publica (FRANCO, 2015, p. 261).

Tal qual já restou destacado, ainda no curso do período de vacatio legis do novo

inócuo, quando pelo menos uma das partes manifesta, desde logo, o desinteresse em solução autocompositiva. O argumento é o de que um dos princípios reitores da mediação é o da voluntariedade, tanto assim que ninguém pode ser obrigado a prosseguir, contra sua vontade, no procedimento correlato (art. $2^{\circ}, \S 2^{\circ}$, da Lei $n^{\circ}$ 13.140/2015. Por todos, veja-se Alexandre Freitas Câmara (CÂMARA, 2015, p. 199).

$14 \mathrm{O}$ ponto será retomado adiante. 
Código de Processo Civil, sobreveio a Lei de Mediação (Lei nº 13.140/2015).

Referido diploma legislativo reforçou as regras que já estavam inseridas no novo Código de Processo Civil, devotando todo o seu segundo capítulo (a partir do art. 32) à disciplina da utilização dos meios de autocomposição de conflitos dos quais for parte pessoa jurídica de direito público.

A regra do art. 32 franqueia à União e aos demais entes da Federação a possibilidade da criação de câmaras de prevenção e resolução administrativa de conflitos, no âmbito dos respectivos órgãos da Advocacia Pública.

A faculdade parece flexibilizar a imposição que resultou da redação do art. 174 do novo Código de Processo Civil. Tal interpretação não pode prevalecer. A recomendação para que se amplie a noção de acesso à justiça, nela abrangendo os meios aqui designados como integrados de solução de conflitos, é norma fundamental do novo Código de Processo Civil e, portanto, com aptidão para contaminar todo o sistema processual. Assim, malgrado a literalidade do art. 32 da Lei de Mediação, permanece hígida, para os Entes da Federação, a obrigação de criação de câmaras da espécie.

A própria Lei de Mediação evidencia, no art. 33, que enquanto não forem criadas as câmaras de que trata, as mediações poderão ser realizadas segundo as diretrizes traçadas para as mediações comuns (que envolvem particulares).

Não se pode deixar de observar, de qualquer sorte, que a eventual inexistência de tais câmaras não impede a utilização de soluções autocompositivas, a teor do quanto dispõe o art. 175 do novo Código de Processo Civil (SCHWIND e KUKIELA, 2016, p. 338).

Relevante destacar, para os fins da discussão que será travada adiante, que o $\S 3^{\circ}$ do mencionado art. 32 da Lei de Mediação explicita que eventual consenso será reduzido a termo, constituindo, para todos os fins, título executivo extrajudicial.

Importante observar, ademais, que o $\S 4^{\circ}$ do art. 32 da Lei de Mediação afasta da competência das câmaras de mediação as controvérsias que somente possam ser resolvidas por ato ou concessão de direito sujeitos a autorização do Poder Legislativo.

Já o art. 35 da Lei de Mediação cria a possibilidade de transação por adesão, no âmbito da Administração Pública Federal, com fundamento em autorização do Advogado Geral da União baseado em jurisprudência pacífica do Supremo Tribunal Federal ou de tribunais superiores. A transação igualmente pode ser autorizada por parecer do Advogado-Geral da União, devidamente aprovado pelo Presidente da República. A adesão implica renúncia do interessado ao direito sobre o qual se funda a ação ou recurso eventualmente pendente, de 
natureza administrativa ou judicial, notadamente no que diz respeito ao objeto da resolução administrativas (art. $35, \S 4^{\circ}$ ).

\section{LIMITES DA UTILIZAÇÃO DA CONCILIAÇÃO E DA MEDIAÇÃO QUANDO UM DOS ENVOLVIDOS FOR A FAZENDA PÚBLICA}

A atuação da fazenda pública, em juízo ou fora dele, prende-se à regra da legalidade estrita. Importa dizer que o administrador público não pode atuar sem que esteja autorizado por lei.

Referida noção e o dogma da indisponibilidade dos bens e direitos públicos não raras vezes ensejaram oposição de óbices à possibilidade de realização de solução autocompositivas pelas Fazendas Públicas.

O ponto merece revisão. A noção da indisponibilidade vem se relativizando. Não se há de confundir indisponibilidade de direito com intransigibilidade, que só tem lugar quando a lei expressamente veda a transação. Tal é o caso do art. 17 , $\S 1^{\circ}$, da Lei $n^{\circ}$ 8.429/1992 (Lei de Improbidade Administrativa) - única hipótese expressa de vedação de transação no ordenamento jurídico brasileiro (SOUZA, 2012, p. 173). De mais a mais, mesmo que o direito seja indisponível, não há indisponibilidade quanto ao modo do mesmo ser regulado, nada impedindo, em decorrência, que meios de solução consensual de conflitos sejam empregados para tal fim (FACCI, 2015, p. 239-240).

A própria noção de legalidade, ademais, vem sofrendo alteração. A tal respeito, ensina Gustavo Binenbojm que o princípio da legalidade estrita já não é mais altaneiro e soberano como outrora. Importa dizer que a atividade administrativa continua a ser realizada com estrita observância da lei, desde que, evidentemente, ela seja compatível com o Texto Constitucional. Nada obstante, a atividade administrativa pode encontrar fundamento diretamente na Constituição, independente ou para além da lei, ou, eventualmente, legitimar-se perante o Direito mesmo contra a lei, com fulcro em ponderação da legalidade com outros princípios constitucionais. Atividade contra legem, mas com fundamento em otimizada aplicação da Constituição (BINENBOJM, 2008, p. 37-38).

Assim, possível, em tese, a adoção de soluções autocompositivas, mesmo que não haja norma legal expressa autorizando-a (respeitados, por evidente, os limites constitucionais impostos à indisponibilidade dos bens e patrimônio público).

Não se pode ignorar, de outra parte, que há muito vigem, no ordenamento jurídico 
brasileiro, regras que admitem expressamente a submissão das Fazendas Públicas a soluções autocompositivas - providência somente agora prodigalizada.

Assim é que há muito funciona, no âmbito federal, a CCAF (Câmara de Conciliação e Arbitragem da Administração Federal), órgão da AGU (Advocacia-Geral da União), cujo objetivo é resolver administrativamente os litígios entre os órgãos e entidades federais, evitando judicialização.

De outra parte, diversos diplomas legislativos previram a possibilidade de termos de ajustamento de conduta.

Assim é que o Estatuto da Criança e do Adolescente (Lei no 8.069/90) previu, em seu art. 211, a possibilidade de acertos da estirpe (terno de ajuste de conduta).

Da mesma forma, o Código de Defesa do Consumidor (Lei nº 8.078/90), ao alterar o texto da Lei da Ação Civil Pública (Lei no 7.347/85), admitiu a possibilidade de termos de ajustamento de conduta sobre diversos temas (por exemplo, meio ambiente, patrimônio cultural, histórico e paisagístico, ordem econômica etc.).

A legislação de defesa da concorrência (Lei n ${ }^{\circ} 8.884 / 94$ ), por sua parte, autorizou a celebração de compromisso de cessação da conduta abusiva, para suspender ato administrativo sancionador, modelo replicado na legislação mais moderna sobre o tema (Lei $\mathrm{n}^{\circ}$ 12.519/2011).

Na seara ambiental, explícita a autorização inserida na Lei n 9.605/1998, art. 79-A.

No mesmo sentido, o Estatuto do Idoso (Lei no 10.741/2003, art. 74, X).

Por fim, a lei de regência das agências reguladoras outorga-lhes o poder-dever de dirimir, no âmbito administrativo, as divergências entre as concessionárias, permissionárias, autorizadas etc. Vejam-se, por exemplo, Lei $n^{\circ}$ 9.427/1996 (ANEEL, art. 3º, V), Lei ${ }^{\circ}$ 9.472/1996 (ANATEL, art. 19, XVII), Lei no 9.478/1997 (ANP, art. 20), Leis no 9.656/1998 e 9.961/200 (ANS, arts. 29, § $1^{\circ}$ e $4^{\circ}$, XXXIX, respectivamente), Lei ${ }^{\circ}$ 12.154/2009 (PREVIC, art. $\left.2^{\mathrm{o}}, \mathrm{VIII}\right)^{15}$.

Claro a mais não poder, portanto, que há muito é possível a realização de soluções autocompositivas no âmbito da Administração Pública (notadamente, nos exemplos expostos, no âmbito da Administração Pública Federal).

A própria Lei de Mediação (Lei no 13/140/2015), por outro lado, tratou de enfrentar dois outros dos óbices usualmente opostos à possibilidade de soluções autocompositivas. Em um caso, afastou a possibilidade de autocomposição. No outro, viabilizou-a.

15 Para enumeração mais completa, Lúcio Picanço Facci (FACCI, 2015, p. 238). 
O primeiro deles diz com aquelas controvérsias que somente podem ser resolvidas por ato ou concessão de direito sujeito a autorização do Poder Legislativo. Quanto a tais casos, há vedação expressa de submissão da questão às câmaras de mediação (art. $32, \S 4^{\circ}$ ). Por extensão, referidas questões também não poderão ser solucionadas por intermédio dos meios integrados de solução de conflitos, mesmo fora das câmaras de mediação.

Já a possibilidade de ofensa à isonomia foi superada de maneira arguta pelo legislador. De fato, contrapunha-se que a celebração de avenças entre a Administração Pública e os administrados (e/ou com outros órgão da mesma esfera e/ou de outra esfera de poder) poderia ensejar favorecimentos indevidos. Como viabilizar fiscalização?

A solução apontada pelo legislador foi a mais simples possível: instituiu-se a possibilidade de adesão aos termos de mediação já realizada (art. 35).

Criaram-se condições para adesão que, ademais, são coerentes com o sistema de precedentes vinculantes que o novo Código de Processo Civil visa institucionalizar. Assim, o Advogado-Geral da União poderá autorizar a adesão, se baseado em jurisprudência pacífica do Supremo Tribunal Federal ou de tribunais superiores. Se não houver entendimento consolidado, parecer do Advogado-Geral da União precisa ser aprovado pelo Presidente da República. A adesão implica, como já restou dito anteriormente, renúncia do interessado ao direito sobre o qual se funda a ação ou recurso eventualmente pendente, de natureza administrativa ou judicial, notadamente no que diz respeito ao objeto da resolução administrativa (art. 35, § $4^{\circ}$ ). A administração Pública ainda fixará, também por resolução administrativa, as condições da transação por adesão.

Ao impor condições à adesão, o legislador impediu que a respectiva concretização dependesse apenas da demonstração pelo administrado (e/ou de outro órgão da administração pública) que se encontra exatamente na mesma situação da composição tomada como paradigma.

Mesmo assim, a regra referida representa avanço, a recomendar sua replicação nas searas estaduais, municipais e distrital.

Questão recorrente, quando se cuida da possibilidade da realização de soluções autocompositivas pelas Fazendas Públicas, diz com a necessidade de autorização legislativa expressa para que o advogado público celebre avença.

Na esfera federal, autorizações da estirpe são algumas vezes concedidas (veja-se o caso dos procuradores do INSS, que possuem alçada para celebrar avenças no âmbito dos juizados 
especiais federais) ${ }^{16}$.

A postura encontra agora reforço na regra do art. 40 da Lei de Medição. Deveras, ali restou assentado que servidores e empregados públicos que participarem do processo de composição extrajudicial do conflito somente poderão ser responsabilizados civil, administrativa ou criminalmente quando, mediante dolo ou fraude, receberem qualquer vantagem patrimonial indevida, permitirem ou facilitarem sua recepção por terceiro, ou para tal concorrerem.

Indispensável que Estados, Municípios e o Distrito Federal superem a clássica desconfiança em seus próprios agentes - sim, no final das contas, esta é a razão que inviabiliza maior utilização das soluções autocompositivas - e editem leis que não apenas instituam as câmaras de mediação e resolução de conflitos, nos moles determinados pela Lei de Mediação, mas igualmente estabeleçam alçadas e matérias que, sem resquício de dúvida, poderão ser solucionadas por mediação ou conciliação.

A omissão ameaça transformar em letra morta as regras do novo Código de Processo Civil e da Lei de Mediação.

Há, ao final, dois entraves de difícil superação.

O primeiro diz com a impossibilidade de respeito à regra da confidencialidade (art. 30 da Lei de Mediação), por incompatibilidade com o princípio da publicidade dos atos da Administração Pública, agora reforçado pela Lei do Acesso à Informação - Lei no ${ }^{\circ}$ 12.527/2011 (PEIXOTO, 2016. p. 352-353).

A impossibilidade de observância da aludida regra seguramente inviabilizará acertos, seja pelo temor de que informações estratégicas saiam do espaço próprio da mediação (ou conciliação), seja pelo receio de que as mesmas informações possam ser utilizadas em contenda judicial posterior, se malograda a intenção autocompositiva. Óbice virtualmente intransponível, portanto.

Por derradeiro, há a questão do sistema precatorial.

Sabido a mais não poder que a Administração Pública somente pode quitar obrigações judicialmente impostas por meio da execução e/ou do cumprimento de sentença previstos em lei (conforme se cuide de título extrajudicial ou de título judicial, respectivamente), de que resultará a expedição de precatório ou de requisição de pequeno valor, consoante o montante

16 Há autorizações pontuais, normalmente relacionadas com temas ou matérias cujo desfecho já está delineado em jurisprudência de tribunais superiores, condicionadas à edição de súmula administrativa ou de instrução normativa a cargo do Advogado-Geral da União. 
do crédito.

De outra parte, pagamentos realizados diretamente carecem de prévia previsão orçamentária.

Ora, mesmo autorizando a Administração Pública a utilizar-se dos meios autocompositivos, impondo, inclusive, a criação de câmaras de mediação, nem o novo Código de Processo Civil, nem tampouco a lei de Mediação cogitaram de recomendar a criação de reserva orçamentária para a realização dos pagamentos que possam resultar de acertos eventualmente celebrados.

A inexistência de disponibilidade orçamentária certamente tornará virtualmente inócua a possibilidade de solução autocompositiva, ao menos no que diz respeito àquelas situações das quais resulte, para a Administração Pública, o dever de pagar.

De fato, expressamente dispôs o art. $32, \S 3^{\circ}$, da Lei de Mediação que, se houver consenso, o acordo será reduzido a termo e constituirá título executivo extrajudicial.

Qual a vantagem para a parte contrária em obter tal título, se não houver previsão orçamentária para pagamento? Nenhuma.

De fato, se não houver pagamento, o credor precisará, para receber o que lhe é devido, promover execução. Nela, o devedor (no caso, a Administração Pública) poderá deduzir qualquer defesa que lhe teria sido lícito fazer em ação de conhecimento (art. 910, § $2^{\circ}$, do novo Código de Processo Civil).

Não há, pois, sentido prático algum. Poder-se-ia argumentar que, em tais casos, seria interessante a celebração de avença no curso do processo (durante a audiência inicial do procedimento, prevista o art. 334 do novo Código de Processo Civil, por exemplo). A situação do credor tornar-se-ia ainda pior. Mesmo com título judicial em mãos, o credor não poderia receber, salvo por precatório ou por requisição de pequeno valor. E se, só para argumentar, o Administrador Público resolvesse antecipar pagamento - porquanto, afinal de contas, tratar-seia de débito judicial resultante de autocomposição -, estaria praticando quebra de ordem, violando o sistema precatorial e, como tal, sujeitando-se a imediato sequestro nas contas públicas.

Tal o entendimento há muito sedimentado pelo Supremo Tribunal Federal ${ }^{17}$.

Sendo assim, de nenhuma efetividade a realização de soluções autocompositivas que

17 Rcl 3220 ED, Relator(a): Min. CELSO DE MELLO, Tribunal Pleno, julgado em 24/04/2008, ACÓRDÃO ELETRÔNICO DJe-029 DIVULG 13-02-2013 PUBLIC 14-02-2013, disponível em www.stf.jus.br, acesso em 30/06/2016, 01:23. 
se traduzam na imposição de obrigação de pagar dinheiro ao Poder Público. A situação reclama a existência de previsão orçamentária própria para a celebração de acertos da estirpe, ou de improvável alteração do sistema precatorial de pagamento dos débitos fazendários, constitucionalmente fixado.

\section{CONCLUSÃO}

A edição da Resolução no 125, do Conselho Nacional de Justiça, em 2010, deflagrou política pública de estimulo à utilização dos meios antes designados de alternativos para a solução dos conflitos.

A superveniência do novo Código de Processo Civil, aprovado em 2015 e em vigor desde 18 de março de 2016, importa na introdução de um novo modelo processual, policêntrico, dialógico.

Busca-se, então, efetivar a ideia de sistema multiportas de solução de conflitos. A via da outorga da prestação jurisdicional deixa de ser a preferencial para a composição dos litígios acaso surgidos no seio da sociedade. Ganham relevo a mediação e a conciliação, métodos de solução autocompositiva, erigidas, ao lado da arbitragem (método heterocompositivo) em meios integrados de solução de conflitos. Supera-se a ideia de meios alternativos.

Ainda durante o período de vacatio legis do novo Código de Processo Civil, sobreveio a nova Lei de Mediação, contaminada do mesmo espírito inovador.

Um e outra preocupam-se em ofertar soluções para o maior litigante habitual (repeat player) que há: as Fazendas Públicas. Admitem que as Fazendas Públicas tomem parte em conciliações e mediações e impõem a criação de centros de mediação.

Enfrentam alguns dos óbices usualmente opostos à possibilidade de que as Fazendas Públicas tomem parte em conciliações e mediação, mas negligenciam duas questões sem solução fácil: (1) a compatibilização da confidencialidade das conciliações e mediações com a publicidade que deve presidir qualquer ação estatal e (2) a inexistência de previsão orçamentária específica para pagamento imediato das obrigações de pagar acaso resultantes de conciliações ou mediações, pena de, deixando os interessados submetidos ao regime percatorial e/ou das requisições de pequeno valor, torná-las inócuas.

Ainda há muito por caminhar. 


\section{REFERÊNCIAS BIBLIOGRÁFICAS}

BINENBOJM, Gustavo. Uma Teoria do Direito Administrativo. Direitos Fundamentais, Democracia Constitucionalização. 2. ed. Rio de Janeiro: Renovar, 2008.

CABRAL, Antônio do Passo. A duração razoável do processo e a gestão do tempo no projeto de Novo CPC. In FREIRE, Alexandre; DANTAS, Bruno; NUNES, Dierle; DIDIER Jr., Fredie; MEDINA, José Miguel Garcia; FUX, Luiz; CAMARGO, Luiz Volpe e OLIVEIRA, Pedro Miranda de (Org.). Novas Tendências do Processo Civil. Vol. 2. Salvador: Juspodivm, 2014, p. 101-122.

CÂMARA, Alexandre Freitas. O Novo Processo Civil Brasileiro. São Paulo: Atlas, 2015.

CAMBI, Eduardo e VASCONCELOS, João Paulo. Desjudicialização de políticas públicas e o Novo Código de Processo Civil - contributo do Ministério Público e da Advocacia Pública à solução extrajudicial de conflitos. In José Henrique Mouta e CUNHA, Leonardo Carneiro da. Advocacia Pública. Coleção Repercussões do Novo CPC, vol. 3. Salvador: Juspodivm, 2015, p. 83-110.

CAPPELETTI, Mauro; GARTH, Bryant. Acesso à justiça. Porto Alegre: Sérgio Antonio Fabris, 1988

CUNHA, Leonardo Carneiro da. A Fazenda Pública em Juízo. 13. ed. Rio de Janeiro: Gen/Forense, 2016.

FACCI, Lúcio Picanço. A utilização de meios consensuais de resolução de conflitos pela Administração Pública e o Novo Código de Processo Civil. In ARAÚJO, José Henrique Mouta e CUNHA, Leonardo Carneiro da. Advocacia Pública. Coleção Repercussões do Novo CPC, vol. 3. Salvador: Juspodivm, 2015, p. 229-248.

FRANCO, Marcelo Veiga. Câmaras de Mediação e conciliação na Fazenda Pública: o artigo 174 do Novo Código de Processo Civil como contribuição para o acesso à justiça 
“desjudicializado". In ARAÚJO, José Henrique Mouta e CUNHA, Leonardo Carneiro da. Advocacia Pública. Coleção Repercussões do Novo CPC, vol. 3. Salvador: Juspodivm, 2015, p. 249-261.

NUNES, Dierle; TEIXEIRA, Ludmila. Acesso à Justiça Democrático. Brasília: Gazeta Jurídica, 2013.

PEIXOTO, Ravi. Primeiras impressões sobre os meios consensuais de resolução de conflitos pelo poder público e as alterações promovidas pelo CPC/2015 e pela Lei 13.140/2015. In TALAMINI, Eduardo. Processo e Administração Pública. Coleção Repercussões do Novo CPC, vol. 10. Salvador: Juspodivm, 2016, p. 3347-364.

SALES, Lilia Maia de Morais. Justiça e mediação de conflitos. Belo Horizonte: Del Rey, 2003.

SCHWIND, Rafael Wallbach e KUKIELA, Marina. Câmaras de conciliação e mediação da Administração Pública: comentários ao artigo 174 do novo Código de Processo Civil. In TALAMINI, Eduardo. Processo e Administração Pública. Coleção Repercussões do Novo CPC, vol. 10. Salvador: Juspodivm, 2016, p. 327- 345.

SOUZA, Luciane Moesa de. Meios consensuais de solução de conflitos envolvendo entes públicos. Negociação, mediação e conciliação na esfera administrativa e judicial. Belo Horizonte: Fórum, 2012.

TARTUCE, Fernanda. Mediação nos conflitos civis. 2. ed. São Paulo: Gen/Método, 2015.

THEODORO Jr., Humberto; NUNES, Direle; BAHIA, Alexandre melo Franco e PEDRON, Flávio Quinaud. Novo CPC - Fundamentos e Sistematização. 2. ed. Rio de Janeiro: Forense, 2015.

VIANNA, Luiz Werneck; CARVALHO, Maria Alice R. de; MELO, Manel Palácios Cunha e BURGOS, Marcelo Baumann. Corpo e Alma da Magistratura Brasileira. 3. ed. Rio 
de Janeiro: Editora Renavam, 1997.

WATANABE, Kazuo. Política judiciária nacional de tratamento adequado dos conflitos de interesse: utilização dos meios alternativos de resolução de controvérsias. In $\mathbf{O}$ processo em perspectiva: jornadas brasileiras de direito processual. São Paulo: RT, 2013.

Sítios eletrônico consultados: www.stf.jus.br e www.cnj.jus.br 